\title{
Thermal paper can replace typewriter correction paper in Emlen funnels
}

\author{
Henrik Mouritsen - Gesa Feenders · \\ Arne Hegemann · Miriam Liedvogel
}

Received: 24 February 2009/Accepted: 13 May 2009/Published online: 18 June 2009

(C) Dt. Ornithologen-Gesellschaft e.V. 2009

Emlen funnels are small funnel-shaped orientation cages used to record the spontaneously directed migratory restlessness (Zugunruhe) of night-migratory songbirds (Emlen and Emlen 1966). Today, almost every group studying the compass orientation capabilities of migratory songbirds uses the Emlen funnel method (e.g., Sandberg et al. 2002; Wiltschko and Wiltschko 2003; Ritz et al. 2004; Muheim et al. 2006; Chernetsov et al. 2008). This method provides the most reliable and cost effective tool to analyze the spontaneous directional preference of many migratory songbirds during the migratory season. Results from Emlen funnel experiments also play a key role in the current rush towards understanding how the magnetic compass sense in migratory songbirds works (e.g., Ritz et al. 2004; Mouritsen and Ritz 2005).

When Emlen first invented the method (Emlen and Emlen 1966), he used an inkpad at the bottom of the cage and lined the walls of the funnel with blotting paper to score the ink marks as a measure of the bird's directional choice. Later, Rabøl (1979) got the idea to use typewriter correction paper on the walls instead of ink and blotting paper to record the birds' directional preferences. This was a significant improvement for the birds, since "Rotkehlchen" (Robin Erithacus rubecula) would no longer become "Blaukehlchen" (Bluethroat Luscinia svecica) after several nights hopping on the inkpad. The refined typewriter correction paper version of the Emlen funnel was adopted by virtually every study using Emlen funnels after 1980 (e.g.,

Communicated by F. Bairlein.

H. Mouritsen $(\bowtie) \cdot$ G. Feenders · A. Hegemann · M. Liedvogel AG Neurosensorik/Animal Navigation, Oldenburg University, 26111 Oldenburg, Germany

e-mail: henrik.mouritsen@uni-oldenburg.de
Mouritsen and Larsen 1998; Sandberg et al. 2002; Wiltschko and Wiltschko 2003; Ritz et al. 2004; Muheim et al. 2006). However, over the last 10 years, researchers using the Emlen funnel method have been challenged by the disappearance of typewriters, which has made it exceedingly difficult to find a reliable supplier of appropriately sized rolls of typewriter correction paper needed to do Emlen funnel experiments.

The Wiltschko-lab in Frankfurt (e.g., Wiltschko and Wiltschko 2003; Ritz et al. 2004) were instrumental in convincing one of the producers of typewriter correction paper to make a final production run, which helped many colleagues stock up on paper for several years. Unfortunately, the chalk-like coating on typewriter correction paper tends to harden with time, which means that it becomes more and more difficult to accurately score scratches on the paper. In addition to this problem, our stock ran out several years ago, which made us initiate a search for an alternative solution, as going back to the ink method would not be acceptable for animal welfare reasons.

First, we visited the local crime unit to see if fingerprint detection dust could help us. It did not work because its function is based on the fat on the fingers which the dust sticks to. But the claws of birds are normally fat free and thus claw marks cannot be visualized with fingerprint detection dust. Second, we got the idea that maybe the paper used in trucks to record their speed (tachopgraph charts, "Fahrtenschreiberpapier" in German) could also be used to record the scratches left in Emlen funnels by migratory birds. As a result, we tested various such papers from several different producers with variable success until we received a sample of "Thermal paper" product number "SC55" from the company "Blumberg Systempapiere", Kalkumerstrasse 46, 40885 Ratingen-Lintorf, Germany; 
Fig. 1 Thermal paper. a Roll of thermal paper as delivered from Blumberg $\mathrm{GmbH}$ placed on our paper cutting table. b Thermal paper in a funnel after a 1 -h test of a well-oriented European Robin (Erithacus rubecula). c Scratches on thermal paper still in the funnel. d Close-up of the scratches
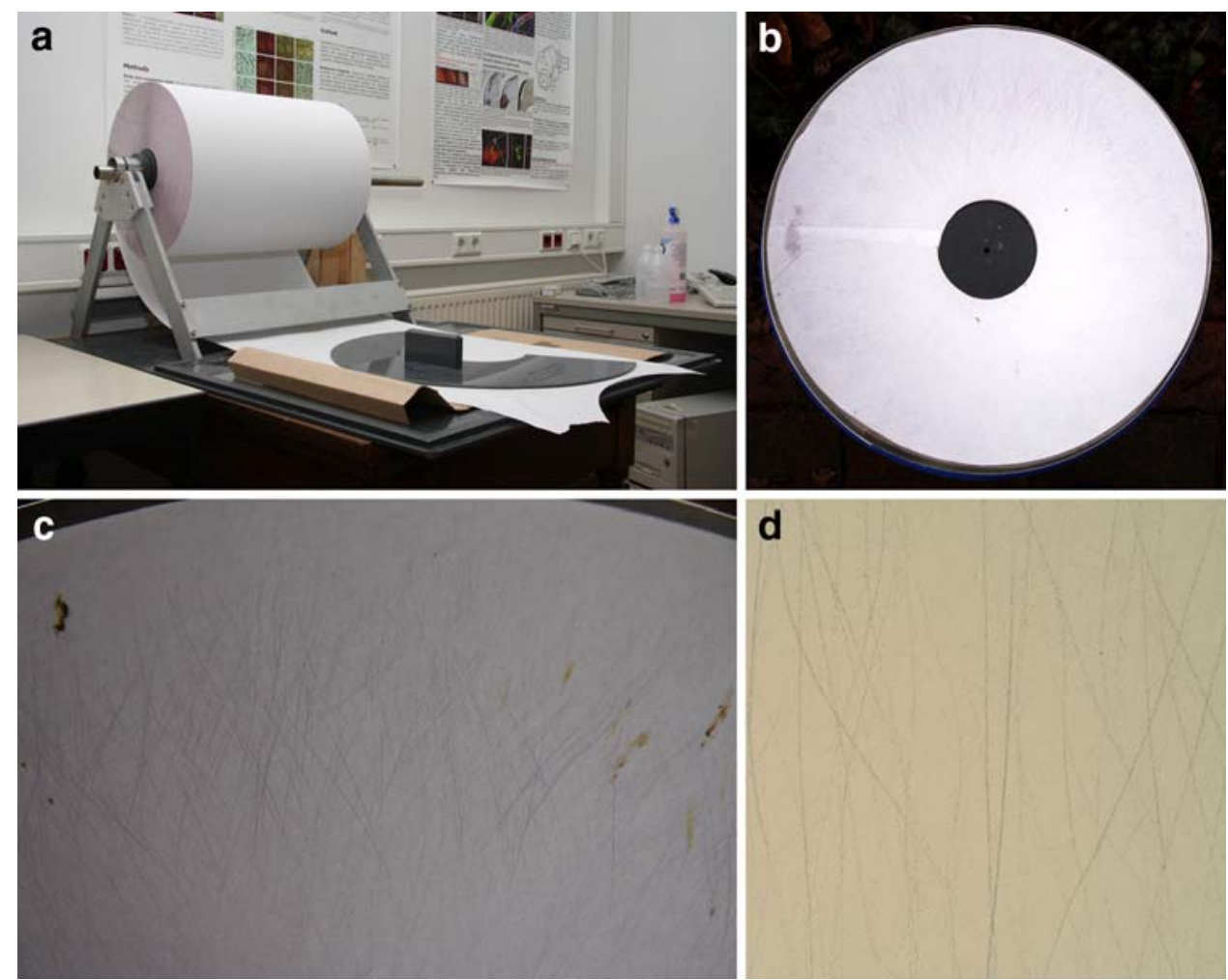

email: info@blumberg.de; Phone: +49 (0)2102 38030. This paper worked extraordinarily well for our purpose (Fig. 1).

Thermal paper changes color irreversibly from white to blue when it is heated. The friction between the bird's claws and the paper produces heat, which results in very distinct blue scratches whenever the bird jumps or flutters up the side of the funnel. Based on this simple principle, thermal paper can be used to very reliably record the migratory restlessness of the birds.

In fact, thermal paper is significantly more sensitive than typewriter correction paper, and the scratches are nice and narrow, which make them easier to count than scratches on typewriter correction paper. The thermal paper works very well both indoors and outdoors, since it is not very sensitive to humidity or temperature. The very local temperature rise caused by the claws sliding over the paper is large enough in all experimental conditions under which we tested the paper (indoors and outdoors from down to about $0^{\circ} \mathrm{C}$ up to about $30^{\circ} \mathrm{C}$ ). Furthermore, during the 3 years we have used the paper, we have observed no degradation of the scratches on previously used papers. We pack used papers in large cardboard folders, place the folders in light-tight plastic bags and store them in a dry, not too hot, location. Under these storage conditions, the data will probably be available for evaluation and re-checking for decades. Likewise, but in contrast to type-writer correction paper, unused rolls of thermal paper can be kept for years without quality deterioration.

In conclusion, we suggest that everybody in the field of bird migration and navigation, who is experiencing problems with getting hold of fresh typewriter correction paper, should switch to thermal paper. "Blumberg Systempapiere" delivers the thermal paper in $0.48 \times 2,400 \mathrm{~m}$ rolls and the minimum order is three rolls. In our laboratory, we currently use about one full roll per migratory season.

\section{References}

Chernetsov N, Kishkinev D, Mouritsen H (2008) A long-distance avian migrant compensates for longitudinal displacement during spring migration. Curr Biol 18:188-190

Emlen ST, Emlen JT (1966) A technique for recording migratory orientation of captive birds. Auk 83:361-367

Mouritsen H, Larsen ON (1998) Migrating young Pied flycatchers do not compensate for geographical displacements. J Exp Biol 201:2927-2934

Mouritsen H, Ritz T (2005) Magnetoreception and it use in bird navigation. Curr Opin Neurobiol 15:406-414

Muheim R, Phillips JB, Åkesson S (2006) Polarized light cues underlie compass calibration in migratory songbirds. Science 313:837-839

Rabøl J (1979) Magnetic orientation in night-migrating passerines. Ornis Scand 10:69-75 
Ritz T, Thalau P, Phillips JB, Wiltschko R, Wiltschko W (2004) Resonance effects indicate radical pair mechanism for avian magnetic compass. Nature 429:177-180

Sandberg R, Moore FR, Bäckman J, Löhmus M (2002) Orientation of nocturnally migrating Swainson's thrush at dawn and dusk: importance of energetic condition and geomagnetic cues. Auk 119:201

Wiltschko R, Wiltschko W (2003) Avian navigation: from historical to modern concepts. Anim Behav 65:257-272 